\title{
Radio Pathological Correlation of Thyroid Nodules Using Tirads Based Ultrasound Classification and Bethesda Classification for FNAC: a Prospective Study
}

Richa TIWARI', Ruchi GUPTA², Amit Kumar VERMA³ ${ }^{3}$ Sanjeev KUMAR ${ }^{4}$, Yogita KATIYAR ${ }^{5}$

\begin{abstract}
Background: Thyroid gland is afflicted by various pathologies amongst which nodules are the cause of maximum concern because of their malignant potential. With the introduction of high resolution ultrasound and use of Thyroid imaging reporting and data system (TIRADS) classification as a widely used universal grading system, there has been reduced inter-observer variability and increased inter-departmental communication. In this study, we studied the TIRADS ultrasound grading as a screening tool and compared it with the BETHESDA grading on FNAC. Material and methods: 200 patients with thyroid nodules were subjected to ultrasound and USG guided FNAC. Each was assigned a TIRADS and Bethesda grade. Findings were compared to assess the sensitivity, specificity, PPV (positive predictive value) and NPV (negative predictive value) of ultrasound in differentiating benign from malignant nodules. RESULT: Out of 200 nodules examined, 116 nodules belonged to TIRADS 2 while 44, 13 and 27 belonged to TIRADS 3, 4 and 5 respectively. On FNAC, 162 patients belonged Bethesda $2 \& 12,7,15$ and 4 to Bethesda 3, 4, 5 and 6 respectively. The sensitivity, specificity, PPV and NPV of ultrasound were found to be 92.3, 90.8, 60 and $98.75 \%$ respectively. Conclusion: TIRADS is an effective risk stratification system which should be routinely used in our clinical practice as it can predict the possibility of a particular nodule for being malignant to a great extent. Especially keeping in mind its high negative predictive value, FNAC can be deferred in TIRADS 2 patients which form a majority of cases reporting to pathology department for thyroid FNAC.
\end{abstract}

Keywords: TIRADS (thyroid image reporting and data system), thyroid nodules, fine-needle aspiration cytology, Bethesda.

\footnotetext{
${ }^{1}$ Department of Radiodiagnosis, SMMH Medical College, Uttar Pradesh, India

${ }^{2}$ Department of Radiodiagnosis, Indira Gandhi Institute of Medical Sciences, Bihar, India

${ }^{3}$ Department of Radiodiagnosis, King George's Medical University, Uttar Pradesh, India

${ }^{4}$ Department of Community Medicine, SMMH Medical College, Uttar Pradesh, India

${ }^{5}$ Department of Pathology, SMMH Medical College, Uttar

Pradesh, India
}

\section{Corresponding author.}

Sanjeev KUMAR, Department of Community Medicine, SMMH

Medical College, Saharanpur-247001, Uttar Pradesh, India.

E-mail: docsanjeevk179@gmail.com 


\section{INTRODUCTION}

Thyroid gland is afflicted by various pathologies ranging from diffuse enlargement (goiter) to nodular lesions and thyroiditis.

Nodules are the cause of maximum concern among all thyroid pathologies because of their malignant potential. There is a wide range of malignant potential among the clinically or radiologically detected thyroid nodules. The average prevalence of malignancy rates across the world in thyroid nodules, as shown by invasive procedure ranges from 4.0 to $6.5 \% \%^{1,2}$.

The American Thyroid Association defines thyroid nodules as "discrete lesions within the thyroid gland, radiologically distinct from surrounding thyroid paren-

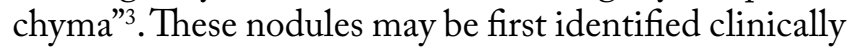
or incidentally on thyroid imaging (incidentalomas) ${ }^{4}$.

Earlier in the absence of any standardized system of USG reporting. there was difficult communication between radiologists and endocrinologists. Then, the introduction of the Thyroid Imaging Reporting and Data System (TIRADS) by the American College of Radiologists ${ }^{5}$ was an attempt to study and compare sonographic findings of thyroid nodules to cytological findings. This system was originally proposed by Horvath et al. ${ }^{6}$ as a risk stratification system and subsequently modified by Jin Kwak et al. ${ }^{7}$ into a more practical and reproducible format.

TIRADS classification originally proposed by Horvath et al. ${ }^{6}$ and subsequently modified by Kwak et al. ${ }^{7}$ is as follows: TIRADS 1 -normal thyroid gland; TIRADS 2-benign lesions (including simple cyst, spongiform nodule, isolated macro calcification and typical sub acute thyroiditis) ${ }^{8}$; TIRADS 3-probably benign lesions (no suspicious ultrasound [US] features or nodules that are iso or hyperechogenic); TIRADS 4suspicious lesions, TIRADS 5-probably malignant lesions (all five suspicious US features); and TIRADS 6-biopsy-proven malignancy.

Ultrasound imaging characteristics which were considered suspicious were (I) solid nodule (II) microcalcifications, (III) irregular or microlobulated margins, (IV) marked hypoechogenicity and (V) taller-thanwide shape. TIRADS 4 a had a $5-10 \%$ risk of malignancy, while $4 \mathrm{~b}$ and $4 \mathrm{c}$ had a $10-80 \%$ risk of malignancy. TIRADS 5 category lesions have $80 \%$ risk of malignancy ${ }^{6}$.

The fine-needle aspiration method for studying the thyroid was first developed in Sweden in the $\mathrm{Ru}^{-}$ diunhelmet hospital of Stockholm in the 1950s'. Bethesda classification system established a standar- dized, category-based reporting system for thyroid FNACs ${ }^{10}$. It is as follows: Bethesda Class I- inadequate or unsatisfactory, Bethesda Class II -benign thyroid nodules, Bethesda Class III -follicular lesion of undetermined significance, Bethesda Class IV -(suspicious for) follicular neoplasm, Bethesda Class V-suspicious for malignancy and Class VI-malignant.

\section{MATERIAL AND METHODS}

This study received approval from the institute's ethics committee (IEC) for human research. Informed consent was obtained from each participant, according to the Declaration of Helsinki, and the IEC approved pro forma.

The study was a prospective study and patients who had thyroid nodule in B-mode ultrasound were subjected to fine needle aspiration cytology (FNAC). Sample size was kept as 200 and study duration was 18 months (October 2018-March 2020).

The exclusion criteria were normal thyroid scan (TIRADS 1), proven case of thyroid malignancy (TIRADS 6), and patients who had persistent Bethesda I (non-diagnostic) FNAC after two attempts.

The imaging was done using Esaote machine with high-frequency probe $(3-13 \mathrm{MHz})$. During the procedure, patient lies in supine position with neck slightly extended and high resolution ultrasound examination of thyroid gland was done. The thyroid nodules, if present, were staged according to TIRADS. The neck was then assessed for any enlarged lymph nodes. FNAC of all nodules was done by the radiologist under direct USG guidance. The FNAC samples were read by an experienced pathologist and Bethesda staging was done. The data was subsequently transferred to a $\mathrm{Mi}^{-}$ crosoft Excel 2010 sheet and statistical analysis done using IBM SPSS for Windows version 22.0 (SPSS, Inc., Chicago, IL, USA).

\section{RESULT}

In our study, $80 \%$ of patients (160) were females and two third $(66 \%)$ of patients were between third and sixth decade of life.

A total of 200 nodules were studied and each was assigned a TIRADS and Bethesda grade. On ultrasound, 116 nodules (58\%) belonged to TIRADS 2, 44 (22\%) to category $3,13(6.5 \%)$ and $27(13.5 \%)$ to TIRADS 4 and 5 respectively. On FNAC, 162 patients belonged Bethesda 2,12 to Bethesda 3, while 7,15 and 4 to Bethesda 4, 5 and 6 respectively. These findings have 
Radio Pathological Correlation of Thyroid Nodules Using Tirads Based Ultrasound Classification and Bethesda Classification

Table 1. TIRADS and Bethesda distribution of nodules

\begin{tabular}{|l|c|c|c|c|c|c|}
\hline & BETHESDA 2 & BETHESDA 3 & BETHESDA 4 & BETHESDA 5 & BETHESDA 6 & TOTAL \\
\hline TIRADS 2 & 114 & 2 & - & - & - & - \\
\hline TIRADS 3 & 38 & 4 & 1 & 1 & 16 \\
\hline TIRADS 4 & 5 & 3 & 2 & 2 & 3 & 13 \\
\hline TIRADS 5 & 5 & 3 & 4 & 12 & 27 & $\mathbf{4}$ \\
\hline TOTAL & $\mathbf{1 6 2}$ & $\mathbf{1 2}$ & $\mathbf{7}$ & $\mathbf{1 5}$ & $\mathbf{2 0 0}$ \\
\hline
\end{tabular}

been tabulated in Table 1 .

For all the calculations, TIRADS 4/ 5 and BETHESDA 4/5/6 considered positive for malignancy and the rest as negative.

Thus $80 \%$ of nodules (160) belonged to benign and probably benign categories on ultrasound, i.e. TIRADS 2 and TIRADS 3 while 20\% belonged to suspicious (TIRADS 4) and malignant (TIRADS 5) categories. Similarly approx $81 \%$ nodules belonged to benign (Bethesda 2) grade on FNAC while only 13 were malignant (Bethesda 4,5 and 6).

Out of 116 nodules belonging to TIRADS 2, none turned out to be Bethesda 4/5/6, thus risk of malignancy in TIRADS 2 was $0 \%$. Out of the two indeterminate FNAC (Bethesda III) amongst these, one patient insisted on repeat FNAC where it was shown be benign hyperplastic nodule (Bethesda II) and other showed no increase in size on interval follow up on 3/6/9 months.

The risk of a malignant FNAC in TIRADS 3, 4 and 5 was $4.5,38.4$ and $70.4 \%$ respectively. Thus TIRADS 4 and 5 have 8.5 and 15.6 times chances of malignancy as compared to TIRADS 3 respectively.

Similarly the chances of a benign FNAC (Bethesda II) in TIRADS 2, 3, 4 and 5 was 98.3, 86.3, 38.5 and $18.5 \%$ respectively.

TIRADS and BETHESDA results were cross-tabulated in a $2 \times 2$ table (Table 2) with TIRADS $4 / 5$ and BETHESDA 4/5/6 considered positive for malignancy and the rest as negative.

Using this table, the sensitivity, specificity, PPV (positive predictive value) and NPV(negative predictive value) of ultrasound were calculated (considering
FNAC as the gold standard) using the below formulas and were found to be as follows:

- Sensitivity (true positive rate) equivalent to a/ $a+c-92.3 \%$.

- Specificity (true negative rate) equivalent to $d /$ b+d- $90.8 \%$.

- PPV (proportion of people with a positive test result who actually have the disease) $a / a+b-60 \%$.

- NPV (proportion of those with a negative result who do not have the disease) $d / c+d-98.75 \%$.

- Also, there was significant association found between TIRADS and Bethesda ( $p$ value was $<0.05$ using Chi-square test).

\section{DISCUSSION}

The assessment of thyroid is a multipronged approach involving history with clinical examination, thyroid function tests, ultrasound thyroid and US-guided FNAC.

However until recently, the USG evaluation of thyroid lesions was less standardized. Then with the introduction of TIRADS and the endorsement of this classification system by the American College of Radio$\operatorname{logist}^{6}$, we have a reproducible risk stratification system similar to BIRADS grading system for breast lesions. This system attempts to correlate sonographic features to cytological classification and gives an estimate of chances of malignancy in a particular nodule.

The sonological features included in our study are echogenicity, microcalcifications, taller than wider shape, presence of suspicious lymph node, irregular margins, and peripheral halo. It is to be emphasized here

Table $2.2 \times 2$ table for diagnostic test results

\begin{tabular}{|c|c|c|c|}
\hline & \multicolumn{2}{|r|}{ FNAC } & \multirow[b]{2}{*}{ TOTAL } \\
\hline & POSITIVE(malignancy positive) & NEGATIVE(malignancy negative) & \\
\hline $\begin{array}{l}\text { TIRADS (SCREENING TEST) } \\
\text { POSITIVE } \\
\text { NEGATIVE }\end{array}$ & $\begin{array}{l}24(a) \\
02(c)\end{array}$ & $\begin{array}{l}16(b) \\
158(d)\end{array}$ & $\begin{array}{l}40(a+b) \\
160(c+d)\end{array}$ \\
\hline TOTAL & $26(a+c)$ & $174(b+d)$ & 200 \\
\hline
\end{tabular}


Table 3. Comparative evaluation of risk of malignancy amongst various TIRADS grades

\begin{tabular}{|l|c|c|c|c|c|c|}
\hline & $\begin{array}{c}\text { Our study } \\
\text { (in \%) }\end{array}$ & $\begin{array}{c}\text { Singaporewalla et al } \\
\text { (in \%) }\end{array}$ & $\begin{array}{c}\text { Periakaruppan et al } \\
\text { (in \%) }\end{array}$ & $\begin{array}{c}\text { Horvath et al } \\
\text { (in \%) }\end{array}$ & $\begin{array}{c}\text { Kwak et al } \\
\text { (in \%) }\end{array}$ & $\begin{array}{c}\text { Moifo et al } \\
\text { (in \%) }\end{array}$ \\
\hline TIRADS 2 & 0 & 0 & 0 & 0 & 0 & 0 \\
\hline TIRADS 3 & 4.5 & 9.5 & 2.2 & 14.1 & 1.7 & 2.2 \\
\hline TIRADS 4 & 38.4 & 33.3 & 38.5 & 45 & $3-3-72.4$ & $5.9-57.9$ \\
\hline TIRADS 5 & 70.4 & 60 & 77.8 & 89.6 & 87.5 & 100 \\
\hline
\end{tabular}

Table 4. Comparative evaluation of test characteristics in various studies

\begin{tabular}{|l|c|c|c|}
\hline & OUR STUDY & Singaporewalla et al. & Periakaruppan et al. \\
\hline SENSITIVITY & 92.3 & 70.6 & 92.3 \\
\hline SPECIFICITY & 90.8 & 90.4 & 94.1 \\
\hline PPV & 60 & 60 & 54.5 \\
\hline NPV & 98.75 & 93.8 & 99.4 \\
\hline
\end{tabular}

that it is not the presence or the absence of a single feature on ultrasound which is important. Rather the presence of at least two of the USG features is more accurate in differentiating a benign nodule and a highrisk nodule for malignancy ${ }^{11,12}$.

In our study, we found that more than the half of thyroid nodules (56\%) belonged to TIRADS 2 having $0 \%$ chances of malignancy. So we can take a more informed decision about subsequent FNAC which although is a readily available and inexpensive test but also minimally invasive at the same time. But it is a prerequisite that the radiologist performing ultrasound and guided FNACs has had a good learning curve and has audited his/her results in comparison to FNAC.

Comparing our results with previous studies, female predisposition ${ }^{13}$ was similar to the studies of G. Periakaruppan et al. ${ }^{14}$ and $\mathrm{K} \mathrm{P}$ Gupta et al. ${ }^{15}$ where $84 \%$ and $74 \%$ patients were females respectively. This might be explained by the effect of estrogen and progesterone, as pregnancy has been shown to be related to increased nodule size and new nodule development ${ }^{16}$.

Comparative evaluation of risk of malignancy for each TIRADS grade was done with previous studies and is shown in Table 3.

The findings are similar in all except for slightly reduced percentage of malignancy in TIRADS 4 and 5 of Singaporewalla et al. ${ }^{17}$ as here only Bethesda 5 and 6 were included in malignant and not Bethesda 4 unlike others.
Table 4 compares the test characteristics (sensitivity, specificity, PPV and NPV) of our screening test (TIRADS) with those of prior studies by Singaporewalla et al. ${ }^{18}$ and Periakaruppan et al. ${ }^{15}$ and shows similar results.

One of the shortcomings of our study was that TIRADS 4 was considered as a single class and not classified into $4 \mathrm{~A}, 4 \mathrm{~B}$ and $4 \mathrm{C}$ which vary widely as far as malignant potential is considered.

\section{CONCLUSION}

TIRADS is an ultrasound-based effective risk stratification system correlating cytological and radiological features. It can predict the chances of a particular thyroid nodule for being malignant to a great extent. Especially keeping in mind its high negative predictive value and the fact that TIRADS 2 nodules have $0 \%$ chances of malignancy, FNAC can be deferred in these TIRADS 2 patients. It will also help reduce the burden on pathology department as these patients form the bulk of nodules reporting for thyroid FNAC.

Compliance with ethics requirements: The authors declare no conflict of interest regarding this article. The authors declare that all the procedures and experiments of this study respect the ethical standards in the Helsinki Declaration of 1975, as revised in 2008(5), as well as the national law. Informed consent was obtained from all the patients included in the study. 


\section{References}

1. De Matos PS, Ferreira AP, Ward LS. Prevalence of papillary microcarcinoma of the thyroid in Brazilian autopsy and surgical series. Endocr Pathol. 2006;17:165-73.

2. Kovacs GL, Gonda G, Vadasz G, Ludmany E, Uhrin K, Gorombey $Z$, et al. Epidemiology of thyroid microcarcinoma found in autopsy series conducted in areas of different iodine intake. Thyroid. 2005;15:152-7.

3. Cooper DS, Doherty GM, Haugen BR, Kloos RT, Lee SL, Mandel SJ, et al. Revised American Thyroid Association management guidelines for patients with thyroid nodules and differentiated thyroid cancer: 2009;19:1167-214

4. Singh S, Singh A, Khanna AK. Thyroid incidentaloma. Indian J Surg Oncol. 2012;3(3):173-181.

5. Grant EG, Tessler FN, Hoang JK, Langer JE, Beland MD, Berland $L L$, et al: Thyroid ultrasound reporting lexicon: White paper of the ACR Thyroid Imaging, Reporting and Data System (TIRADS) Committee. J Am Coll Radiol 2015; 12(12):1272-1279

6. Horvath E, Majlis S, Rossi R, Franco C, Niedmann JP, Castro A, et al.: An ultrasonogram reporting system for thyroid nodules stratifying cancer risk for clinical management. J Clin Endocrinol Metab 2009; 94(5):1748-1751

7. Kwak JY, Han KH, Yoon JH, Moon HJ, Son EJ, Park SH, et al. Thyroid imaging reporting and data system for us features of nodules: A step in establishing better stratification of cancer risk. Radiology. 2011;260(3):892-9.

8. Moifo B, Takoeto EO, Tambe J, Blanc F, Fotsin JG: Reliability of thyroid imaging reporting and data system (TIRADS) classification in differentiating benign from malignant thyroid nodules. Open J Radiol 2013; 03:103-107
9. Galera-Davidson H, Gonzalez-Campora R. Thyroid. In: Bibbo M, Wilbur D, editors. Comprehensive Cytopathology. 3rd ed. Philadelphia, PA: Saunders Elsevier; 2008. p. 633-8.

10. Cibas ES, and. Ali SZ: The Bethesda System for Reporting Thyroid Cytopathology, Am J Clin Pathol 2009;132(5):658-665

11. Papini E. The dilemma of non-palpable thyroid nodules. J Endocrinol Invest. 2003;26(1):3-4

12. Frasoldati A, Valcavi R. Challenges in neck ultrasonography: Lymphadenopathy and parathyroid glands. Endocr Pract. 2004 10(3):261-8.

13. Desforges JF, Mazzaferri EL. Management of a solitary thyroid nodule. N Eng J Med. 1993;328(8):553-9.

14. Periakaruppan G, Seshadri K, Vignesh Krishna G, Mandava R, Venkata Sai P, Rajendiran S: Correlation between Ultrasoundbased TIRADS and Bethesda System for Reporting Thyroidcytopathology: 2-year Experience at a Tertiary Care Center in India: Indian J Endocrinol Metab 2018 22(5): 651-655.

15. Gupta KP, Gupta A, Gupta A. Radiopathological Correlation of Thyroid Masses: A Prospective Study. Int J Sci Stud 2019;7(3):89-93.

16. Kung AW, Chau MT, Lao TT, Tam SC, Low LC. The effect of pregnancy on thyroid nodule formation. J Clin Endocrinol Metab. 2002;87:1010-4.

17. Singaporewalla RM, Hwee J, Lang TU, Desai V. Clinico-pathological Correlation of Thyroid Nodule Ultrasound and Cytology Using the TIRADS and Bethesda Classifications. World J Surg 2017;41(7):1807-11. 
